\title{
Association between Air Pollution and Lung Function Growth in Southern California Children
}

\author{
W. JAMES GAUDERMAN, ROB MCCONNELL, FRANK GILLILAND, STEPHANIE LONDON, DUNCAN THOMAS, \\ EDWARD AVOL, HITA VORA, KIROS BERHANE, EDWARD B. RAPPAPORT, FRED LURMANN, \\ HELENE G. MARGOLIS, and JOHN PETERS
}

\begin{abstract}
Department of Preventive Medicine, University of Southern California School of Medicine, Los Angeles; Sonoma Technology Inc., Petaluma; Air Resources Board, State of California, Sacramento, California; and National Institute of Environmental Health Sciences, Research Triangle Park, North Carolina
\end{abstract}

\begin{abstract}
Average growth of lung function over a 4-yr period, in three cohorts of southern California children who were in the fourth, seventh, or tenth grade in 1993, was modeled as a function of average exposure to ambient air pollutants. In the fourth-grade cohort, significant deficits in growth of lung function (FEV FVC, $_{1}$ maximal midexpiratory flow [MMEF], and $\mathrm{FEF}_{75}$ ) were associated with exposure to particles with aerodynamic diameter less than 10 $\mu \mathrm{m}\left(\mathrm{PM}_{10}\right), \mathrm{PM}_{2.5}, \mathrm{PM}_{10}-\mathrm{PM}_{2.5}, \mathrm{NO}_{2}$, and inorganic acid vapor $(\mathrm{p}<$ 0.05 ). No significant associations were observed with ozone. The estimated growth rate for children in the most polluted of the communities as compared with the least polluted was predicted to result in a cumulative reduction of $3.4 \%$ in $\mathrm{FEV}_{1}$ and $5.0 \%$ in MMEF over the 4-yr study period. The estimated deficits were generally larger for children spending more time outdoors. In the seventh- and tenth-grade cohorts, the estimated pollutant effects were also negative for most lung function measures, but sample sizes were lower in these groups and none achieved statistical significance. The results suggest that significant negative effects on lung function growth in children occur at current ambient concentrations of particles, $\mathrm{NO}_{2}$, and inorganic acid vapor.
\end{abstract}

The acute health consequences of breathing polluted air are well documented, ranging from increased cardiorespiratory morbidity and mortality to increased prevalence of respiratory symptoms and decrements in lung function (1-4). Chronic health effects from exposure to air pollution have been suggested by previous studies, although whether chronic effects occur at current ambient concentrations remains uncertain (1, 2, 5-7). Children may be a particularly vulnerable population because they spend more time outdoors, are generally more active, and have higher ventilation rates than adults (8).

One approach to assessing the potential chronic effects of air pollution is to determine how pollution affects lung function growth. The broad range of air quality in southern California offers the opportunity to investigate the health effects of exposure to several pollutants, including ozone, nitrogen oxides, particles, and acids. In 1993, we initiated a 10 -yr prospective study of respiratory health in children from 12 southern California communities. In this report, we examine the longitudinal lung function data from the first $4 \mathrm{yr}$ of follow-up and analyze the relationship between air pollution concentrations and lung function growth.

(Received in original form September 23, 1999 and in revised form May 2, 2000) Supported in part by the California Air Resources Board (Contract A033-186), the National Institute of Environmental Health Sciences (Grant SP30ES0704802), the Environmental Protection Agency (Cooperative Agreement CR822685), and the Hastings Foundation.

Correspondence and requests for reprints should be addressed to W. James Gauderman, Department of Preventive Medicine, USC School of Medicine, 1540 Alcazar St., CHP 220, Los Angeles, CA 90089. E-mail: jimg@rcf.usc.edu

Am J Respir Crit Care Med Vol 162. pp 1383-1390, 2000

Internet address: www.atsjournals.org

\section{METHODS}

\section{Study Subjects}

Twelve communities within a 200-mile radius of Los Angeles were selected in 1993 based on their historical air pollution levels. In each community, approximately 150 children in grade four, 75 in grade seven, and 75 in grade 10 were selected from public schools. Information concerning medical history, residential history, housing characteristics, and time spent outdoors was obtained by questionnaire. Additional characteristics of the study design have been previously described $(6,7)$. Spirometric evaluations of the children were conducted annually from 1993 to 1997 for the fourth- and seventh-grade cohorts, and from 1993 to 1995 for the tenth-grade cohort. A total of 3,035 children had at least two evaluations during this period. The study protocol was approved by the institutional review board for human studies at the University of Southern California, and informed written consent was provided by parents for all study subjects.

\section{Pulmonary Function Testing}

Pulmonary function tests (PFTs) were performed at schools during the morning and early afternoon hours of spring. Each subject was asked to perform up to seven maximal forced expiratory flow-volume maneuvers using one of six rolling-seal spirometers (Spiroflow; P.K. Morgan Ltd., Gillingham, UK), from which FVC, FEV 1 , maximal midexpiratory flow (MMEF), and forced expiratory flow rate at $75 \%$ of expired FVC $\left(\mathrm{FEF}_{75}\right)$ were recorded. A more detailed description and procedures for maneuver selection, spirometer calibration, and quality control have been previously reported (7).

\section{Air Pollution Data}

Air pollution monitoring stations were established in each of the 12 communities as a part of the study design, with measurements for all pollutants at all sites available from 1994 onward. All stations monitored hourly concentrations of ozone $\left(\mathrm{O}_{3}\right)$, nitrogen dioxide $\left(\mathrm{NO}_{2}\right)$, and particles with aerodynamic diameter less than $10 \mu \mathrm{m}\left(\mathrm{PM}_{10}\right)$. Two-week integrated samplers were used to measure $\mathrm{PM}_{2.5}$ and acid vapor. For statistical analysis, we computed the annual averages of the $24 \mathrm{~h}$ averages of $\mathrm{O}_{3}, \mathrm{PM}_{10}$, and $\mathrm{NO}_{2}$, the annual average of 10:00 A.M. to 6:00 P.M. levels of $\mathrm{O}_{3}$, the annual averages of the 2-wk averages of $\mathrm{PM}_{2.5}$ and inorganic acid vapor $\left(\mathrm{HCl}+\mathrm{HNO}_{3}\right)$, and the difference between annual average $\mathrm{PM}_{10}$ and $\mathrm{PM}_{2.5}$. In addition, 3-yr mean levels (1994 to 1996) in each community were computed for all pollutants.

\section{Statistical Analysis}

Linear regression methods were used to determine whether, over the $4 \mathrm{yr}$ of follow-up, average lung function growth rates of the children in each community were associated with the corresponding average pollutant levels in those communities. The outcome data consisted of 11,536 PFTs recorded from 1993 to 1997 on 3,035 study subjects in the 12 communities. Because lung function increases nonlinearly from childhood through adolescence (9), all analyses were performed separately within grade cohort (fourth, seventh, or tenth grade in 1993). A set of three regression models was used to adequately account for time, subject, and community-specific effects.

The first model was a linear regression of PFT (natural-log transformed) on age, with indicator variables for subject to obtain a separate intercept and growth slope for each child. Adjustment was made for subject- and time-specific covariates, including height (natural-log 
TABLE 1

CHARACTERISTICS OF THE STUDY POPULATION

\begin{tabular}{|c|c|c|c|c|c|c|c|c|c|c|c|c|}
\hline & & \multirow{2}{*}{$\begin{array}{c}\text { No. of } \\
\text { Subjects* }\end{array}$} & \multirow{2}{*}{$\begin{array}{c}\text { Mean No. } \\
\text { PFTs }\end{array}$} & \multirow{2}{*}{$\begin{array}{c}\text { Female } \\
\text { Sex } \\
(\%)\end{array}$} & \multicolumn{3}{|c|}{ Grade Cohort (\%) } & \multirow{2}{*}{$\begin{array}{c}\text { Ever } \\
\text { Asthma } \\
(\%)\end{array}$} & \multirow{2}{*}{$\begin{array}{l}\text { Gas } \\
\text { Stove } \\
(\%)\end{array}$} & \multirow{2}{*}{$\begin{array}{c}\text { Passive } \\
\text { Smoke } \\
(\%)\end{array}$} & \multirow{2}{*}{$\begin{array}{l}\text { Pets } \\
(\%)\end{array}$} & \multirow{2}{*}{$\begin{array}{c}\text { Time } \\
\text { Outdoors } \\
(\%)\end{array}$} \\
\hline & & & & & 4 th & 7 th & 10th & & & & & \\
\hline Alpine & $(\mathrm{AL})$ & 252 & 3.8 & 51 & 51 & 25 & 24 & 14 & 46 & 19 & 88 & 51 \\
\hline Atascadero & (AT) & 233 & 3.9 & 59 & 49 & 30 & 21 & 22 & 76 & 12 & 91 & 58 \\
\hline Lake Arrowhead & $(\mathrm{LA})$ & 286 & 3.9 & 52 & 52 & 27 & 21 & 14 & 86 & 19 & 86 & 48 \\
\hline Lake Elsinore & (LE) & 258 & 3.7 & 45 & 49 & 24 & 27 & 16 & 75 & 30 & 87 & 56 \\
\hline Lancaster & $(\mathrm{LN})$ & 212 & 3.6 & 51 & 52 & 26 & 22 & 14 & 89 & 23 & 72 & 54 \\
\hline Lompoc & (LM) & 248 & 3.6 & 50 & 39 & 27 & 34 & 12 & 82 & 18 & 78 & 60 \\
\hline Long Beach & $(\mathrm{LB})$ & 257 & 3.7 & 53 & 53 & 25 & 22 & 12 & 82 & 15 & 58 & 45 \\
\hline Mira Loma & $(\mathrm{ML})$ & 262 & 3.8 & 52 & 52 & 27 & 21 & 11 & 94 & 27 & 90 & 52 \\
\hline Riverside & (RV) & 285 & 3.8 & 53 & 49 & 30 & 21 & 16 & 89 & 19 & 76 & 49 \\
\hline San Dimas & (SD) & 252 & 3.9 & 53 & 47 & 27 & 26 & 18 & 90 & 21 & 74 & 52 \\
\hline Santa Maria & (SM) & 248 & 3.6 & 52 & 48 & 26 & 26 & 14 & 85 & 18 & 55 & 49 \\
\hline Upland & (UP) & 242 & 4.0 & 49 & 51 & 24 & 25 & 16 & 73 & 13 & 79 & 52 \\
\hline All & & 3,035 & 3.8 & 52 & 50 & 26 & 24 & 15 & 81 & 20 & 78 & 52 \\
\hline
\end{tabular}

* Number of subjects with at least 2 pulmonary function tests from 1993 to 1997.

$\dagger$ Percent of hours spent outdoors between 2:00 P.M. and 6:00 P.M.. over 10 weekdays.

transformed), weight, body mass index, height-by-age interaction, report of asthma activity or cigarette smoking in the previous year, report of recent exercise, and interactions of each of these variables with sex. Also included as adjustment variables were room temperature and barometric pressure on the day of the test, sets of dummy variables for field technician and spirometer. Lung function growth slopes were scaled to a child with average height growth within each cohort.

The second model was a linear regression of the subject-specific adjusted growth slopes estimated from the first model on indicator variables for community, to obtain the annual average lung function growth rate in each community. Adjustment was made for subjectspecific covariates, including sex, race/ethnicity (Asian, African-American, non-Hispanic white, Hispanic, other), and baseline report of doctor-diagnosed asthma. Additional variables, including report of hay fever, health insurance, regular vitamin use, and the presence in the home of mildew, pests, cockroaches, house plants, an air conditioner, or water damage were not significantly associated with any lung function growth measure at the 0.15 significance level, making them unlikely confounding variables. Because incorporation of these covariates would reduce sample sizes owing to missing values, they were excluded as adjustment variables in all models. Carpeting in the home was marginally associated with reduced MMEF $(\mathrm{p}=0.09)$ and $\mathrm{FEF}_{75}(\mathrm{p}=0.09)$. Models for these PFTs were estimated both with and without adjustment for carpeting, but in no case did adjustment alter an air pollution effect by more than $3 \%$ of the unadjusted estimate. For this reason, and because $7 \%$ of subjects would be excluded for missing carpet information, results described in the next section are based on the models without adjustment for this covariate. The residuals from both the first and second regression models satisfied the
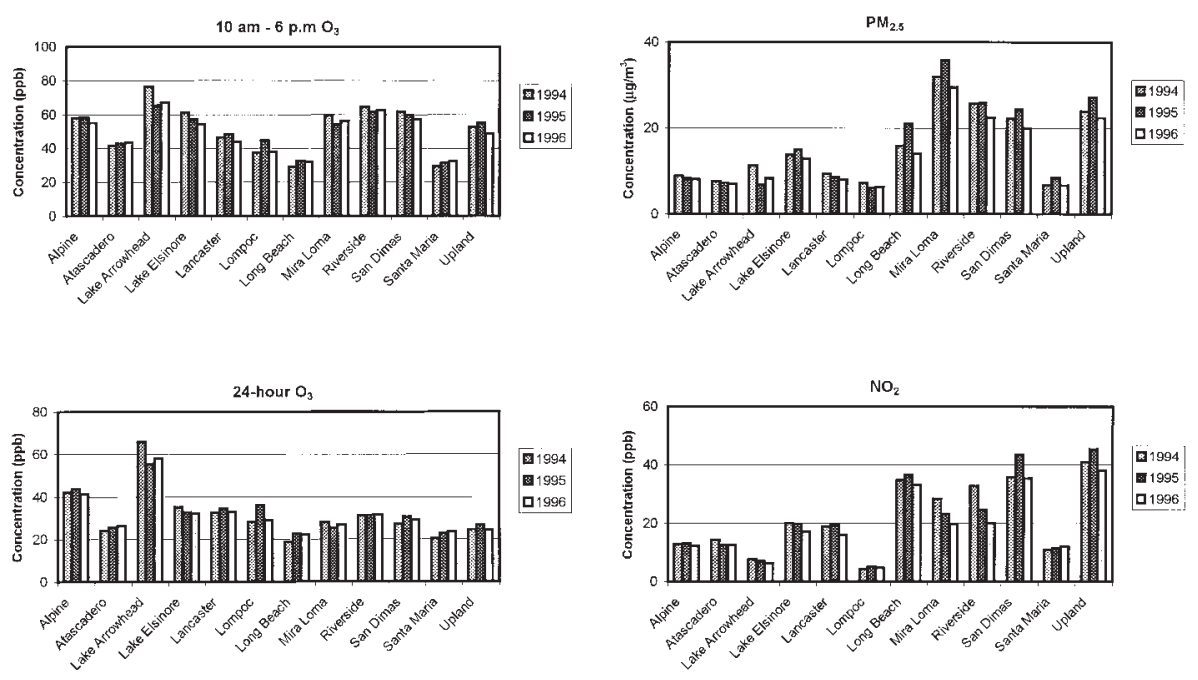

Figure 1. Average annual pollutant concentrations in the 12 study communities.
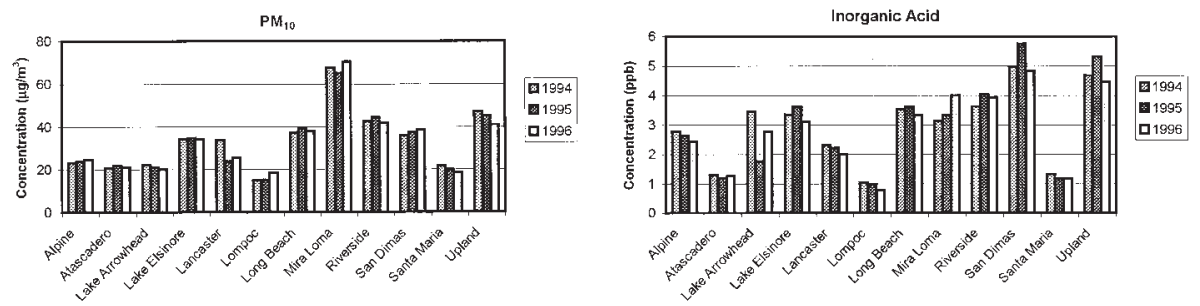
TABLE 2

CORRELATIONS AMONG COMMUNITY MEAN POLLUTANT LEVELS OVER THE STUDY PERIOD

\begin{tabular}{lcccccc}
\hline Pollutant* & $\mathrm{O}_{3}$ & $\mathrm{PM}_{10}$ & $\mathrm{PM}_{2.5}$ & $\mathrm{PM}_{10}-\mathrm{PM}_{2.5}$ & $\mathrm{NO}_{2}$ & $\begin{array}{c}\text { Inorganic } \\
\text { Acid }\end{array}$ \\
\hline $\mathrm{O}_{3}$ (10 A.M.-6 P.M.) & $0.69^{\dagger}$ & 0.28 & 0.35 & 0.15 & 0.06 & 0.50 \\
$\mathrm{O}_{3}$ & - & -0.32 & -0.32 & -0.29 & -0.49 & -0.07 \\
$\mathrm{PM}_{10}$ & - & - & $0.96^{\ddagger}$ & $0.92^{\ddagger}$ & $0.65^{\S}$ & $0.68^{\S}$ \\
$\mathrm{PM}_{2.5}$ & - & - & - & $0.76^{\dagger}$ & $0.74^{\S}$ & $0.79^{\dagger}$ \\
$\mathrm{PM}_{10}-\mathrm{PM}_{2.5}$ & - & - & - & - & 0.44 & 0.43 \\
$\mathrm{NO}_{2}$ & - & - & - & - & - & $0.87^{\ddagger}$ \\
\hline
\end{tabular}

* 24-h average (unless otherwise noted) pollution level from 1994-1996.

$\dagger \mathrm{p}<0.005$.

$\ddagger \mathrm{p}<0.0005$

$\S p<0.05$

assumptions of normality and homoscedasticity, indicating a good fit of the linear models to the lung function data.

The 12 adjusted community-average lung growth rates from the second model were compared graphically with community mean concentrations of each pollutant, and a third linear regression was used to quantify the change in annual growth per unit increase in pollutant level. The parameter of primary interest was the slope from this third regression. These slopes were reported as the difference in estimated percent growth rate per year between the highest and lowest observed community mean levels of each pollutant, with negative differences indicating reduced growth with increased exposure. In addition to modeling the effect of each pollutant univariately, we considered all possible two-pollutant models, obtained by regressing the community-average lung growth rates on a pair of pollutants simultaneously.

For estimation and testing hypotheses, the three regression models described previously were combined into a single, linear mixed model, so that all parameters were mutually adjusted for one another and the resulting pollution effect estimates properly accounted for the different number of observations provided by each subject. The MIXED procedure in SAS (10) was utilized to fit the models, and a two-sided alternative and 0.05 significance level were used for each hypothesis test.

Additional analyses were conducted to explore the robustness of pollutant effect estimates. Models were also estimated after stratifying the data based on sex, asthma status at baseline, and time spent outdoors. The latter variable was obtained from the baseline questionnaire as the number of weekday hours spent outdoors between 2:00 P.M. and 6:00 P.M. over a 10-weekday period. Responses to this question were used to stratify subjects into either a "more outdoors" or "less outdoors" group, based on whether they fell above or below the mean of $20.8 \mathrm{~h}(52 \%$ of $40 \mathrm{~h})$.

\section{RESULTS}

The distribution of subjects with at least two PFTs during the study period is shown in Table 1 . The sample included 1,498 fourth-graders in 1993, 802 seventh-graders, and 735 tenthgraders, with an average of 3.8 PFTs per child. Approximately $15 \%$ of subjects reported a history of doctor-diagnosed asthma at baseline, a proportion that varied from 11\% (Mira Loma) to $22 \%$ (Atascadero) across communities. The prevalence of three indoor sources of air pollutants, passive tobacco smoke, gas stove, and the presence of pets, also varied across communities.

There was substantial variation in annual average pollutant concentrations across the 12 communities, with little year-toyear deviation in levels within each community (Figure 1). From least to most polluted community, pollutant concentrations varied by a factor of approximately 2.5 for daytime and 24-h ozone, 4 for $\mathrm{PM}_{10}, 5$ for $\mathrm{PM}_{2.5}, 8$ for $\mathrm{NO}_{2}$, and 5 for inorganic acid. Table 2 shows correlation coefficients between community mean pollutant levels over the study period. Four of the pollutants $\left(\mathrm{PM}_{10}, \mathrm{PM}_{2.5}, \mathrm{NO}_{2}\right.$, and inorganic acid) were
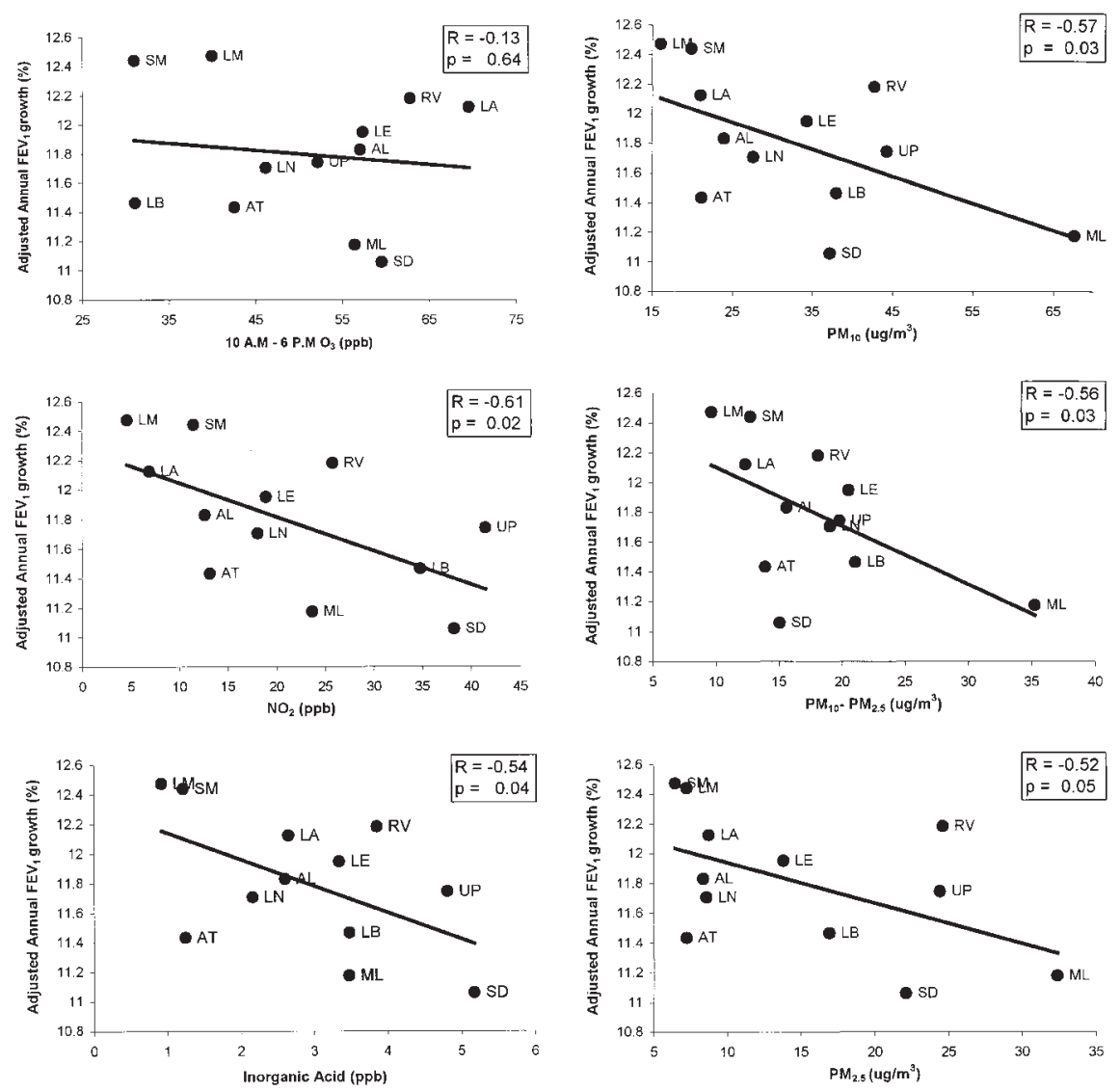

Figure 2. Adjusted average annual $\mathrm{FEV}_{1}$ growth rates for the fourth-grade cohort in the 12 communities versus the mean pollutant levels over the study period. The two-letter abbreviations for each community are shown in Table 1 . 
TABLE 3

DIFFERENCE IN ANNUAL PERCENT GROWTH RATES FROM THE LEAST TO MOST POLLUTED COMMUNITY, BY GRADE COHORT

\begin{tabular}{|c|c|c|c|c|c|c|c|}
\hline \multirow[b]{3}{*}{ Pollutant } & \multirow[b]{3}{*}{ PFT } & \multicolumn{2}{|c|}{ 4th Grade } & \multicolumn{2}{|c|}{ 7th Grade } & \multicolumn{2}{|c|}{ 10th Grade } \\
\hline & & \multicolumn{2}{|c|}{ Difference in Growth* } & \multicolumn{2}{|c|}{ Difference in Growth* } & \multicolumn{2}{|c|}{ Difference in Growth* } \\
\hline & & $\%$ & $(95 \% \mathrm{Cl})$ & $\%$ & $(95 \% \mathrm{Cl})$ & $\%$ & $(95 \% \mathrm{Cl})$ \\
\hline \multirow[t]{4}{*}{$\mathrm{O}_{3}(10-6)$} & FVC & -0.22 & $(-0.79,0.36)$ & -0.10 & $(-0.68,0.47)$ & 0.11 & $(-0.84,1.07)$ \\
\hline & $\mathrm{FEV}_{1}$ & -0.19 & $(-0.99,0.62)$ & 0.20 & $(-0.41,0.81)$ & 0.24 & $(-1.03,1.54)$ \\
\hline & MMEF & -0.24 & $(-1.41,0.95)$ & -0.37 & $(-2.20,1.50)$ & 0.29 & $(-3.50,4.23)$ \\
\hline & $\mathrm{FEF}_{75}$ & -0.85 & $(-2.38,0.70)$ & -0.31 & $(-1.95,1.35)$ & 0.49 & $(-3.36,4.49)$ \\
\hline \multirow[t]{4}{*}{$\mathrm{O}_{3}$} & FVC & 0.17 & $(-0.79,1.15)$ & 0.39 & $(-0.51,1.29)$ & 0.03 & $(-1.57,1.65)$ \\
\hline & $\mathrm{FEV}_{1}$ & 0.56 & $(-0.73,1.87)$ & 0.83 & $(-0.12,1.79)$ & 0.79 & $(-1.33,2.95)$ \\
\hline & MMEF & 0.96 & $(-0.84,2.79)$ & 0.51 & $(-2.45,3.56)$ & 0.35 & $(-5.94,7.07)$ \\
\hline & $\mathrm{FEF}_{75}$ & 0.69 & $(-1.88,3.32)$ & 0.38 & $(-2.13,2.95)$ & 1.08 & $(-5.34,7.92)$ \\
\hline \multirow[t]{4}{*}{$\mathrm{PM}_{10}$} & FVC & -0.58 & $(-1.14,-0.02)^{\dagger}$ & -0.45 & $(-1.03,0.13)$ & 0.07 & $(-0.99,1.13)$ \\
\hline & $\mathrm{FEV}_{1}$ & -0.85 & $(-1.59,-0.10)^{\dagger}$ & -0.44 & $(-1.10,0.23)$ & -0.46 & $(-1.84,0.94)$ \\
\hline & MMEF & -1.32 & $(-2.43,-0.20)^{\dagger}$ & -0.48 & $(-2.51,1.59)$ & -0.71 & $(-4.87,3.63)$ \\
\hline & $\mathrm{FEF}_{75}$ & -1.63 & $(-3.14,-0.11)^{\dagger}$ & -0.50 & $(-2.26,1.29)$ & -1.54 & $(-5.61,2.71)$ \\
\hline \multirow[t]{4}{*}{$\mathrm{PM}_{2.5}$} & FVC & -0.47 & $(-0.94,0.01)$ & -0.42 & $(-0.89,0.05)$ & 0.19 & $(-0.68,1.07)$ \\
\hline & $\mathrm{FEV}_{1}$ & -0.64 & $(-1.28,0.01)$ & -0.32 & $(-0.88,0.24)$ & -0.25 & $(-1.41,0.93)$ \\
\hline & MMEF & -1.03 & $(-1.95,-0.09)^{\dagger}$ & -0.29 & $(-1.99,1.44)$ & -0.17 & $(-3.66,3.46)$ \\
\hline & $\mathrm{FEF}_{75}$ & -1.31 & $(-2.57,-0.03)^{\dagger}$ & -0.26 & $(-1.75,1.25)$ & -0.79 & $(-4.27,2.82)$ \\
\hline \multirow[t]{4}{*}{$\mathrm{PM}_{10}-\mathrm{PM}_{2.5}$} & FVC & -0.57 & $(-1.20,0.06)$ & -0.35 & $(-1.02,0.31)$ & -0.17 & $(-1.32,0.99)$ \\
\hline & $\mathrm{FEV}_{1}$ & -0.90 & $(-1.71,-0.09)^{\dagger}$ & -0.49 & $(-1.21,0.24)$ & -0.68 & $(-2.15,0.81)$ \\
\hline & MMEF & -1.37 & $(-2.57,-0.15)^{\dagger}$ & -0.64 & $(-2.83,1.60)$ & -1.41 & $(-5.85,3.25)$ \\
\hline & $\mathrm{FEF}_{75}$ & -1.62 & $(-3.24,0.04)$ & -0.74 & $(-2.65,1.20)$ & -2.32 & $(-6.60,2.17)$ \\
\hline \multirow[t]{4}{*}{$\mathrm{NO}_{2}$} & FVC & -0.53 & $(-1.01,-0.05)^{\dagger}$ & -0.43 & $(-0.93,0.07)$ & -0.23 & $(-1.13,0.68)$ \\
\hline & $\mathrm{FEV}_{1}$ & -0.77 & $(-1.41,-0.13)^{\dagger}$ & -0.41 & $(-1.00,0.17)$ & -0.75 & $(-1.89,0.41)$ \\
\hline & MMEF & -1.08 & $(-2.07,-0.08)^{\dagger}$ & -0.30 & $(-2.07,1.49)$ & -1.13 & $(-4.68,2.56)$ \\
\hline & $\mathrm{FEF}_{75}$ & -1.37 & $(-2.71,-0.01)^{\dagger}$ & -0.32 & $(-1.88,1.26)$ & -1.28 & $(-4.87,2.44)$ \\
\hline \multirow[t]{4}{*}{ Acid } & FVC & -0.57 & $(-1.06,-0.07)^{\dagger}$ & -0.39 & $(-0.93,0.15)$ & -0.23 & $(-1.15,0.70)$ \\
\hline & $\mathrm{FEV}_{1}$ & -0.73 & $(-1.42,-0.03)^{\dagger}$ & -0.18 & $(-0.81,0.44)$ & -0.65 & $(-1.84,0.56)$ \\
\hline & MMEF & -1.03 & $(-2.09,0.05)$ & -0.30 & $(-2.14,1.57)$ & -1.31 & $(-4.93,2.44)$ \\
\hline & $\mathrm{FEF}_{75}$ & -1.47 & $(-2.87,-0.05)^{\dagger}$ & -0.35 & $(-1.99,1.32)$ & -1.11 & $(-4.80,2.71)$ \\
\hline
\end{tabular}

* Community-average growth rates were adjusted for the covariates listed in Methods. Differences in annual percent growth rate are shown per increase in annual average of $38.6 \mathrm{ppb}$ of $\mathrm{O}_{3}$ (10:00 A.M.-6:00 P.M.), $55 \mathrm{ppb}$ of $\mathrm{O}_{3}, 51.5 \mu \mathrm{g} / \mathrm{m}^{3}$ of $\mathrm{PM}_{10}, 25.9 \mu \mathrm{g} / \mathrm{m}^{3}$ of $\mathrm{PM} 2.5$, $25.6 \mu \mathrm{g} / \mathrm{m}^{3}$ of $\mathrm{PM}_{10}-\mathrm{PM}_{2.5}, 36.8 \mathrm{ppb}$ of $\mathrm{NO}_{2}$, and $4.3 \mathrm{ppb}$ of inorganic acid vapor.

${ }^{\dagger} \mathrm{p}<0.05$.

strongly correlated with one another. Coarse thoracic particle level $\left(\mathrm{PM}_{10}-\mathrm{PM}_{2.5}\right)$ was significantly correlated with $\mathrm{PM}_{10}(\mathrm{r}=$ $0.92)$ and $\mathrm{PM}_{2.5}(\mathrm{r}=0.76)$, but not with any other pollutant. The two $\mathrm{O}_{3}$ metrics were significantly correlated with each other $(\mathrm{r}=0.69)$, but not with any of the remaining pollutants.

In the fourth-grade cohort, $\mathrm{FEV}_{1}$ increased at an average rate of $11.8 \%$ per year during the study period, with comparable growth rates in males $(11.7 \%)$ and females $(11.9 \%)$. The average annual $\mathrm{FEV}_{1}$ growth rates were lower in the seventhgrade $(8.0 \%)$ and tenth-grade $(1.7 \%)$ cohorts. In both the seventh- and tenth-grade cohorts, average growth rates for boys $(12.3 \%$ and $3.3 \%$, respectively) were higher than for girls ( $4.6 \%$ and $0.4 \%$, respectively). The magnitudes and patterns of cohort- and sex-specific growth rates were similar for the other PFTs.

For the fourth-grade cohort, Figure 2 shows the adjusted mean $\mathrm{FEV}_{1}$ growth rates in each community, plotted against the corresponding mean concentrations of $\mathrm{PM}_{10}, \mathrm{PM}_{2.5}, \mathrm{PM}_{10^{-}}$ $\mathrm{PM}_{2.5}, \mathrm{O}_{3}, \mathrm{NO}_{2}$, and inorganic acid vapor, with the fitted regression line and correlation coefficient. Across the 12 communities, $\mathrm{FEV}_{1}$ growth rates ranged from $11.1 \%$ (San Dimas) to $12.5 \%$ (Lompoc). From the lowest to highest observed concentrations of each pollutant, the predicted differences in annual growth rate were $-0.85 \%$ for $\mathrm{PM}_{10}(\mathrm{p}=0.026),-0.64 \%$ for $\mathrm{PM}_{2.5}(\mathrm{p}=0.052),-0.90 \%$ for $\mathrm{PM}_{10}-\mathrm{PM}_{2.5}(\mathrm{p}=0.030)$, $-0.77 \%$ for $\mathrm{NO}_{2}(\mathrm{p}=0.019)$, and $-0.73 \%$ for inorganic acid vapor $(\mathrm{p}=0.042)$. The slope with 10:00 A.M.-6:00 P.M. average $\mathrm{O}_{3}$ was negative but nonsignificant. Approximately $35 \%$ of the variance in adjusted community-average growth rates was explained by either $\mathrm{PM}_{10}$ or $\mathrm{NO}_{2}$ concentrations. For $\mathrm{PM}_{10}$ and $\mathrm{PM}_{10}-\mathrm{PM}_{2.5}$, the high concentrations in Mira Loma gave this community a large potential influence on the effect estimates. However, elimination of this community from the analysis resulted in slightly larger effect estimates for both $\mathrm{PM}_{10}$ $(-0.9 \%)$ and $\mathrm{PM}_{10}-\mathrm{PM}_{2.5}(-1.2 \%)$, although the statistical significance for each was reduced $(\mathrm{p}=0.19$ and $\mathrm{p}=0.18$, respectively) owing to the reduced sample size and range of exposure.

Table 3 shows the corresponding differences in growth rate for all the PFTs in the fourth-, seventh-, and tenth-grade cohorts. In the fourth-grade cohort, significant associations were observed between lung function growth and $\mathrm{PM}_{10}, \mathrm{PM}_{2.5}$, $\mathrm{PM}_{10}-\mathrm{PM}_{2.5}, \mathrm{NO}_{2}$, and inorganic acid, with the largest deficits observed for the flow rate measures (MMEF and $\mathrm{FEF}_{75}$ ). Neither metric of ozone was significantly associated with growth in any of the PFTs. In the seventh- and tenth-grade cohorts, almost all effect estimates for $\mathrm{PM}_{10}, \mathrm{PM}_{2.5}, \mathrm{PM}_{10}-\mathrm{PM}_{2.5}, \mathrm{NO}_{2}$, and inorganic acid vapor were negative, but the confidence intervals were wide and none of them achieved statistical significance.

The associations observed in the fourth-grade cohort remained significant in a variety of sensitivity analyses. Table 4 
TABLE 4

DIFFERENCE IN ANNUAL FEV 1 PERCENT GROWTH RATES FROM THE LEAST TO MOST POLLUTED COMMUNITY FOR $\mathrm{PM}_{10}$ AND $\mathrm{NO}_{2}$, FOURTH GRADE COHORT, FROM A VARIETY OF MODELS

\begin{tabular}{|c|c|c|c|c|}
\hline \multirow[b]{3}{*}{ Model } & \multirow{2}{*}{\multicolumn{2}{|c|}{$\frac{\text { Ambient } \mathrm{PM}_{10}}{\text { Difference in Growth* }}$}} & \multirow{2}{*}{\multicolumn{2}{|c|}{$\frac{\text { Ambient } \mathrm{NO}_{2}}{\text { Difference in Growth* }}$}} \\
\hline & & & & \\
\hline & $\%$ & $(95 \% \mathrm{Cl})$ & $\%$ & $(95 \% \mathrm{Cl})$ \\
\hline 1. Main model ${ }^{\dagger}$ & -0.85 & $(-1.59,-0.10)^{\ddagger}$ & -0.77 & $(-1.41,-0.13)^{\ddagger}$ \\
\hline 2. $1+$ gas stove & -0.88 & $(-1.63,-0.13)^{\ddagger}$ & -0.79 & $(-1.43,-0.15)^{\ddagger}$ \\
\hline 3. $1+$ passive smoke & -0.94 & $(-1.71,-0.17)^{\ddagger}$ & -0.83 & $(-1.50,-0.16)^{\ddagger}$ \\
\hline 4. $1+$ pets & -0.80 & $(-1.52,-0.08)^{\ddagger}$ & -0.76 & $(-1.36,-0.15)^{\ddagger}$ \\
\hline 5. 1 , nonasthmatics only & -0.82 & $(-1.48,-0.15)^{\ddagger}$ & -0.68 & $(-1.30,-0.05)^{\ddagger}$ \\
\hline 6. 1 , asthmatics only & -0.75 & $(-2.84,1.38)$ & -1.39 & $(-2.96,0.20)$ \\
\hline
\end{tabular}

* See footnote to Table 3.

$\dagger$ Equivalent to the results for $\mathrm{FEV}_{1}$ in fourth graders shown in Table 3.

${ }^{\ddagger} \mathrm{p}<0.05$.

shows effect estimates for $\mathrm{PM}_{10}$ and $\mathrm{NO}_{2}$ on $\mathrm{FEV}_{1}$ from several models, with the corresponding estimates from Table 3 included for comparison (Model 1). Adjustment for gas stove (Model 2), passive smoke (Model 3), or pets (Model 4) resulted in little change in effect estimates or statistical significance. The associations also remained significant in the subset of nonasthmatic children (Model 5). In asthmatic children (Model 6), although the effect estimates were as large for $\mathrm{PM}_{10}$ and larger for $\mathrm{NO}_{2}$, the sample size was small $(\mathrm{n}=207)$ and neither association achieved statistical significance. Analogous sensitivity modeling of the other PFTs produced results similar to those shown for $\mathrm{FEV}_{1}$.

In two-pollutant models for $\mathrm{FEV}_{1}$, adjustment for community mean concentration of 10:00 A.M.-6:00 P.M. $\mathrm{O}_{3}$ had little impact on the effect estimates or significance levels of any other pollutant (Table 5, column 1). The $\mathrm{O}_{3}$ effect estimates with adjustment for any other pollutant were all close to zero and nonsignificant (Table 5, row 1). In a two-pollutant particle model, both the $\mathrm{PM}_{2.5}$ and $\mathrm{PM}_{10}-\mathrm{PM}_{2.5}$ effect estimates were negative $(-0.54$ and -0.63 , respectively), but each was lower than its corresponding univariate estimate $(-0.64$ and -0.90 , respectively). This reduction of the particle effect estimates in the two-pollutant model is expected given the positive correlation between these pollutants (Table 2). Similarly, the effect estimates for other two-pollutant combinations are less than their corresponding univariate estimates, although in almost all cases they retain their negative sign.

TABLE 5

DIFFERENCE IN ANNUAL FEV 1 PERCENT GROWTH RATES FROM THE LEAST TO THE MOST POLLUTED COMMUNITY, FOURTH-GRADE COHORT, TWO-POLLUTANT MODELS

\begin{tabular}{lcccccr}
\hline & \multicolumn{5}{c}{ Adjustment Pollutant } \\
\cline { 2 - 7 } Main & $\mathrm{O}_{3}(10-6)$ & $\mathrm{PM}_{10}$ & $\mathrm{PM}_{2.5}$ & $\mathrm{PM}_{10}-\mathrm{PM}_{2.5}$ & $\mathrm{NO}_{2}$ & Acid \\
\hline 1. $\mathrm{O}_{3}(10-6)$ & $-\mathbf{0 . 1 9}$ & 0.03 & 0.06 & -0.08 & 0.15 & 0.24 \\
2. $\mathrm{PM}_{10}$ & $-0.86^{\dagger}$ & $-\mathbf{0 . 8 5}$ & -1.27 & -0.54 & -0.48 & -0.56 \\
3. $\mathrm{PM}_{2.5}$ & $-0.67^{\ddagger}$ & 0.37 & $-\mathbf{0 . 6 4}$ & -0.54 & -0.45 & -0.61 \\
4. $\mathrm{PM}_{10}-\mathrm{PM}_{2.5}$ & $-0.89^{\dagger}$ & -0.37 & -0.63 & $-\mathbf{0 . 9 0}$ & -0.61 & -0.65 \\
5. $\mathrm{NO}_{2}$ & $-0.76^{\dagger}$ & -0.50 & -0.60 & -0.56 & $-\mathbf{0 . 7 7}^{\dagger}$ & -0.65 \\
6. Acid & $-0.86^{\dagger}$ & -0.39 & -0.47 & -0.50 & -0.14 & $-\mathbf{0 . 7 3}^{\dagger}$
\end{tabular}

* Each row gives effect estimates for the indicated pollutant, after adjustment for the pollutant listed at the top of the column. Boldface estimates are from the single-pollutant models shown in Table 3. See Table 3, footnote *, for a description of units.

${ }^{\dagger} \mathrm{p}<0.05$

$\ddagger \mathrm{p}<0.10$
The magnitude of air pollutant effects in the fourth-grade cohort was greater in those who spent more time outdoors than in those who spent more time indoors (Table 6). For example, the difference in annual $\mathrm{FEF}_{75}$ growth rate from highest to lowest $\mathrm{NO}_{2}$ concentrations was $-2.49 \%(\mathrm{p}=0.02)$ in more-outdoors children, but only $-1.12 \%(\mathrm{p}=0.35)$ in lessoutdoors children. There were no clear trends in the relationships between lung function growth and ozone as they related to time spent outdoors. In a separate analysis, stratification by sex in the fourth-grade cohort revealed negative effect estimates for particulates, $\mathrm{NO}_{2}$, and inorganic acid vapor in both males and females (data not shown), with no significant difference in effect between the sexes.

Based on the estimated adjusted annual growth rates in the fourth-grade cohort, Table 7 shows estimates of the cumulative deficit in lung function caused by $4 \mathrm{yr}$ of air pollution exposure. Predicted lung function in 1997 for a child exposed to the highest observed concentrations of $\mathrm{PM}_{10}$ or $\mathrm{NO}_{2}$ since 1993 were between $93.9 \%$ and $97.9 \%$ of those predicted for the same child exposed to the lowest observed concentrations. The flow rates (MMEF and $\mathrm{FEF}_{75}$ ) showed larger deficits in predicted lung function than the volume measures ( $\mathrm{FVC}$ and $\left.\mathrm{FEV}_{1}\right)$.

TABLE 6

DIFFERENCE IN ANNUAL PERCENT GROWTH RATES FROM LEAST TO MOST POLLUTED COMMUNITY FOR CHILDREN IN THE FOURTH-GRADE COHORT, STRATIFIED BY TIME OUTDOORS

\begin{tabular}{|c|c|c|c|c|c|}
\hline \multirow[b]{3}{*}{ Pollutant } & \multirow[b]{3}{*}{ PFT } & \multicolumn{2}{|c|}{ More Outdoors* $(n=532)$} & \multicolumn{2}{|c|}{ Less Outdoors ${ }^{*}(n=642)$} \\
\hline & & \multicolumn{2}{|c|}{ Difference in Growth ${ }^{\dagger}$} & \multicolumn{2}{|c|}{ Difference in Growth ${ }^{\dagger}$} \\
\hline & & $\%$ & $(95 \% \mathrm{Cl})$ & $\%$ & $(95 \% \mathrm{Cl})$ \\
\hline \multirow[t]{4}{*}{$\mathrm{O}_{3}(10-6)$} & FVC & 0.12 & $(-0.54,0.78)$ & -0.05 & $(-0.63,0.53)$ \\
\hline & $\mathrm{FEV}_{1}$ & -0.11 & $(-1.19,0.99)$ & -0.10 & $(-0.79,0.60)$ \\
\hline & MMEF & -0.46 & $(-2.52,1.64)$ & 0.16 & $(-1.34,1.69)$ \\
\hline & $\mathrm{FEF}_{75}$ & -0.41 & $(-2.73,1.98)$ & -0.76 & $(-3.15,1.69)$ \\
\hline \multirow[t]{4}{*}{$\mathrm{O}_{3}$} & FVC & 0.41 & $(-0.60,1.43)$ & 0.23 & $(-0.68,1.14)$ \\
\hline & $\mathrm{FEV}_{1}$ & 0.91 & $(-0.64,2.47)$ & 0.76 & $(-0.35,1.87)$ \\
\hline & MMEF & 1.50 & $(-1.40,4.48)$ & 2.16 & $(-0.26,4.64)$ \\
\hline & $\mathrm{FEF}_{75}$ & 1.81 & $(-1.72,5.47)$ & 1.78 & $(-1.97,5.68)$ \\
\hline \multirow[t]{4}{*}{$\mathrm{PM}_{10}$} & FVC & -0.24 & $(-0.91,0.45)$ & -0.60 & $(-1.22,0.01)$ \\
\hline & $\mathrm{FEV}_{1}$ & -0.87 & $(-1.86,0.14)$ & -0.81 & $(-1.57,-0.03)^{\ddagger}$ \\
\hline & MMEF & -1.88 & $(-3.55,-0.17)^{\ddagger}$ & -1.20 & $(-2.86,0.49)$ \\
\hline & $\mathrm{FEF}_{75}$ & -2.34 & $(-4.65,0.03)$ & -0.88 & $(-3.53,1.83)$ \\
\hline \multirow[t]{4}{*}{$\mathrm{PM}_{2.5}$} & FVC & -0.17 & $(-0.74,0.40)$ & -0.45 & $(-0.97,0.07)$ \\
\hline & $\mathrm{FEV}_{1}$ & -0.67 & $(-1.53,0.21)$ & -0.68 & $(-1.32,-0.03$ \\
\hline & MMEF & -1.56 & $(-3.00,-0.10)^{\ddagger}$ & -1.09 & $(-2.49,0.33)$ \\
\hline & $\mathrm{FEF}_{75}$ & -1.92 & $(-3.88,0.08)$ & -1.15 & $(-3.26,1.01)$ \\
\hline \multirow[t]{4}{*}{$\mathrm{PM}_{10}-\mathrm{PM}_{2.5}$} & FVC & -0.27 & $(-1.00,0.46)$ & -0.65 & $(-1.31,0.01)$ \\
\hline & $\mathrm{FEV}_{1}$ & -0.93 & $(-1.98,0.14)$ & -0.75 & $(-1.57,0.07)$ \\
\hline & MMEF & -1.83 & $(-3.73,0.10)$ & -0.98 & $(-2.76,0.83)$ \\
\hline & $\mathrm{FEF}_{75}$ & -2.29 & $(-4.78,0.27)$ & -0.15 & $(-3.13,2.91)$ \\
\hline \multirow[t]{4}{*}{$\mathrm{NO}_{2}$} & FVC & -0.41 & $(-1.02,0.20)$ & -0.30 & $(-0.87,0.28)$ \\
\hline & $\mathrm{FEV}_{1}$ & -1.00 & $(-1.79,-0.21)^{\ddagger}$ & -0.57 & $(-1.29,0.15)$ \\
\hline & MMEF & -1.90 & $(-3.39,-0.39)^{\ddagger}$ & -1.13 & $(-2.68,0.44)$ \\
\hline & $\mathrm{FEF}_{75}$ & -2.49 & $(-4.57,-0.36)^{\ddagger}$ & -1.12 & $(-3.43,1.25)$ \\
\hline \multirow[t]{4}{*}{ Acid } & FVC & -0.33 & $(-0.97,0.32)$ & -0.32 & $(-0.94,0.30)$ \\
\hline & $\mathrm{FEV}_{1}$ & -0.93 & $(-1.87,0.01)$ & -0.55 & $(-1.31,0.23)$ \\
\hline & MMEF & -1.88 & $(-3.58,-0.14)^{\ddagger}$ & -0.89 & $(-2.55,0.80)$ \\
\hline & $\mathrm{FEF}_{75}$ & -2.34 & $(-4.55,-0.08)^{\ddagger}$ & -1.13 & $(-3.60,1.41)$ \\
\hline
\end{tabular}

* More (less) outdoors includes subjects who reported being outdoors more than (less than) $52 \%$ of the hours between 2:00 P.M. and 6:00 P.M. over a 10-d period.

$\dagger$ see footnote to Table 3.

$\mathrm{p}<0.05$. 
TABLE 7

PREDICTED LUNG FUNCTION IN 1997 FOR A CHILD IN THE FOURTH-GRADE COHORT EXPOSED TO 4-yr OF EITHER LOW OR HIGH POLLUTION LEVELS

\begin{tabular}{lcccc}
\hline & $\begin{array}{c}\mathrm{FVC} \\
(\mathrm{ml})\end{array}$ & $\begin{array}{c}\mathrm{FEV}_{1} \\
(\mathrm{ml})\end{array}$ & $\begin{array}{c}\mathrm{MMEF} \\
(\mathrm{ml} / \mathrm{s})\end{array}$ & $\begin{array}{c}\mathrm{FEF}_{75} \\
(\mathrm{ml} / \mathrm{s})\end{array}$ \\
\hline $\begin{array}{l}\text { Mean in } 1993 \\
\text { Predicted in 1997* }\end{array}$ & 2,365 & 2,048 & 2,366 & 1,479 \\
Lowest pollution & 3,713 & 3,238 & 3,695 & 2,403 \\
Highest $\mathrm{PM}_{10}$ & 3,622 & 3,127 & 3,511 & 2,257 \\
& $(97.5 \%)^{\dagger}$ & $(96.6 \%)$ & $(95.0 \%)$ & $(93.9 \%)$ \\
Highest $\mathrm{NO}_{2}$ & 3,637 & 3,145 & 3,549 & 2,284 \\
& $(97.9 \%)$ & $(97.1 \%)$ & $(96.0 \%)$ & $(95.0 \%)$ \\
\hline
\end{tabular}

* Predicted lung function was obtained by applying the estimated adjusted annual growth rates in the least and most polluted communities to the 1993 values. For example, rates used for $\mathrm{FEV}_{1}$ are based on the regression line shown in Figure 2. Lowest pollution corresponds to levels in Lompoc, with average $\mathrm{PM}_{10}=16.1 \mu \mathrm{g} / \mathrm{m}^{3}$ and $\mathrm{NO}_{2}=$ $4.6 \mathrm{ppb}$, while highest $\mathrm{PM}_{10}=67.6 \mu \mathrm{g} / \mathrm{m}^{3}$ (Mira Loma) and highest $\mathrm{NO}_{2}=41.4 \mathrm{ppb}$ (Upland).

${ }^{\dagger}$ Percent of the predicted value for lowest pollution exposure.

\section{DISCUSSION}

In our fourth-grade cohort of southern California children, exposure to ambient particles, $\mathrm{NO}_{2}$, or inorganic acid vapor was associated with reduced lung function growth. Negative pollution effect estimates were observed in both asthmatic and healthy children. In contrast to our previous cross-sectional findings (7), where pollutant effects on lung function level were observed primarily in females, we found no significant difference between the sexes in the relationship between lung function growth and air pollution. Over the $4 \mathrm{yr}$ of follow-up, children exposed to the highest observed concentrations of $\mathrm{PM}_{10}$ were estimated to experience a cumulative deficit of $3.4 \%$ in $\mathrm{FEV}_{1}$ and $6.1 \%$ in $\mathrm{FEF}_{75}$, relative to children exposed to the lowest observed levels. This indicates that pollutants may impair both large and small airway function, although there were larger estimated deficits observed in measures of small airway damage (MMEF and $\left.\mathrm{FEF}_{75}\right)$. In the seventh- and tenth-grade cohorts, confidence intervals on the pollutant effect estimates were wide owing to the smaller sample sizes in these groups, and none of the associations was statistically significant at the 5\% level. However, the pollutant effect estimates were negative in both the seventh- and tenth-grade cohorts, indicating that the deficits observed for children in the fourth-grade cohort are not likely to be reversed as they age through adolescence.

As in any epidemiologic study, it is possible that the observed results are the result of underlying associations of both the outcome and exposure to some confounding variable. In our study, several potential confounders were considered, including personal and housing characteristics and indoor sources of air pollutants, but none explained the observed associations between ambient air pollution and lung function growth. Additional analysis showed that neither air pollution concentrations on the day before to the PFT nor acute respiratory illness on the day of the PFT were confounders. Another potential source of bias in a cohort study is differential loss to follow-up with respect to both exposure and outcome. This could occur, for example, if a child in a polluted community moved away because air pollution was adversely affecting his or her respiratory health. However, baseline lung function levels and community mean ambient pollutant exposure were not significantly different between subjects who left the study within 2 yr of entry compared with those who remained on study, making this an unlikely source of bias.
Ambient air pollution was associated with larger estimated deficits in lung function growth, particularly for MMEF and $\mathrm{FEF}_{75}$, in children who spent more time outdoors than in children who spent more time indoors. Provided exposures are higher in children spending more time outdoors than indoors, this finding is consistent with a detrimental effect of ambient pollutants on lung function growth. The indoor/outdoor (I/O) ratio, i.e., the amount of outdoor air pollutant that penetrates indoors, has an upper bound of 1.0 (complete penetration) and a lower bound of 0.0 (no penetration). Interestingly, the pollutants with lower I/O ratios (e.g., $\mathrm{PM}_{10}-\mathrm{PM}_{2.5}, \mathrm{NO}_{2}$ ) show larger discrepancies in effect estimates between more- and less-outdoor children than $\mathrm{PM}_{2.5}$, which has a high $\mathrm{I} / \mathrm{O}$ ratio. This pattern is what one would expect if exposure to one or more of these ambient pollutants is having an adverse effect. Although indoor concentrations of ozone are known to be much lower than outdoor levels, there were no apparent trends in ozone effect estimates with respect to time spent outdoors.

In southern California, motor vehicle emissions, in conjunction with various photochemical reactions, are a major source of ambient particles, $\mathrm{NO}_{2}$, and inorganic acid (primarily nitric). Due to the high correlation in concentrations across communities, we were unable to identify the independent effects of each pollutant, although our two-pollutant models do suggest that no single pollutant that we measured is responsible for the observed deficits in lung function growth. There may also be an air pollutant we did not specifically measure (e.g., diesel exhaust particles) that is correlated with those we did and that is primarily responsible for the observed health effects. Associations between lung function and mixtures of air pollutants have also been previously demonstrated (7, 11-14).

In prior studies, particulate matter has been associated with chronic respiratory symptoms (15-18) and recently with lung function growth in children (19), although previously reported associations with lung function have been inconsistent (1517). Particle strong acidity, characterized by sulfur dioxide-derived acidic sulfate particles, has been associated with bronchitis (17) and lung function (20). It is unlikely that this pollutant is responsible for our observed effects, because ambient air during the 1990s in southern California had low concentrations of $\mathrm{SO}_{2}$ and acidic sulfate particles. As in most regions, fine and coarse particle concentrations in the Los Angeles air basin arise from different sources (21). The primary sources that contribute to fine particle concentrations are diesel engine exhaust, food cooking operations, wood burning, and fine diameter paved and unpaved road and crustal dust (22). Emissions from gasoline power engines and other combustion sources make smaller contributions. Primary sources for coarse particle concentration are paved and unpaved road dust and crustal material, which accounts for $45 \%$ of the $\mathrm{PM}_{10}$ mass concentration, and transformed sea-salt particles that are formed over the ocean and transported to the basin by prevailing winds. These sources produce a background aerosol that further interacts with gas-phase combustion emissions whose chemical characteristics evolve during atmospheric reactions to produce particulate-phase ammonium nitrate, ammonium sulfate, and secondary organic carbon compounds. The gas-toparticle conversion processes continue as the aerosol ages and moves downwind resulting in increases in concentration and composition changes of particles until fine particle mass is primarily composed of secondary reaction products.

The emission sources and atmospheric processes that produce particulates have implication for the interpretation of our data. Because the processes are coupled, characteristics of 
the atmospheric aerosol are spatially and temporally correlated. Areas with the highest mass concentration of $\mathrm{PM}_{10}$ and $\mathrm{PM}_{2.5}$ also have the highest secondary aerosol concentrations (ammonium nitrate, ammonium sulfate) and the gas phase with the greatest age from time of emission. It follows that any chronic respiratory effects associated with particulate mass concentration might be explained by particle primary sources or by particle composition or concentrations of other pollutants that are positively correlated with the age of the aerosol. Our current exposure data do not permit us to discriminate among these possibilities.

Unlike other atmospheric pollutants, the effect of $\mathrm{NO}_{2}$ has been examined in epidemiologic studies relatively unconfounded by multiple pollutant mixes, because $\mathrm{NO}_{2}$ is common in indoor air contaminated by emissions from pilot lights and gas stoves at concentrations that may approach outdoor levels. Animal studies suggesting that $\mathrm{NO}_{2}$ may enhance the infectivity of respiratory pathogens have resulted in extensive study of the effects of gas stoves on illness and lung function (2). In one of the few prospective studies in humans, Dutch children were followed over a 2-yr period with serial lung function measurements, but there was no consistent relationship between growth of lung function and a single measurement of indoor $\mathrm{NO}_{2}(23)$. In early analyses of data from the Six Cities studies, lower levels of $\mathrm{FEV}_{1}$ and FVC were observed in children living in homes with gas stoves $(24,25)$, but in subsequent analysis there was no evidence that lung function growth was correlated with gas stove exposure (26). In a subsample of children from the Six Cities study for whom indoor $\mathrm{NO}_{2}$ was measured, there was no consistent effect of measured $\mathrm{NO}_{2}$ on lung function level in spite of a relatively strong association between respiratory symptoms and $\mathrm{NO}_{2}(27)$. Other studies of the effect of indoor sources of $\mathrm{NO}_{2}$ on lung function in children have also not been consistent (2).

The high ambient concentration of $\mathrm{NO}_{2}$ is the primary source of gaseous nitric acid present in southern California air. Although there has been little previous epidemiologic study of nitric acid, exposure to 50 parts per billion (ppb) in chamber studies has been shown to result in modest acute reductions in $\mathrm{FEV}_{1}$ among children with asthma (28). In an epidemiologic study of Dutch children, modest acute deficits in flow rates were associated with same-day exposure to low levels of ambient nitrous acid (29), a gaseous acid that exists in equilibrium with nitric acid. In a large cross-sectional study of children in 24 North American cities, decrements in FVC and FEV 1 were associated with chronic exposure to strong acid sulfate aerosols after adjustment for ozone exposure (20). Experimental and toxicologic studies of acid sulfate aerosols suggest that the irritant potential is related to the $\mathrm{H}^{+}$concentration, especially in association with metal ions (1). However, it is not clear that the effects of gaseous nitric acid are the same as for acid sulfate aerosols, even if $\mathrm{H}^{+}$is responsible for lung damage. Gaseous nitric acid may be buffered differently by oral ammonia, or variations in deposition by particle size for sulfate aerosols may result in respiratory effects that differ from those of nitric acid.

In a recent longitudinal study of children in Austria, Frischer and coworkers concluded that exposure to ambient ozone was associated with reduced lung function growth (30), although they also observed significant associations with $\mathrm{NO}_{2}$, $\mathrm{SO}_{2}$, and $\mathrm{PM}_{10}$. Some additional epidemiologic studies have also suggested that chronic exposure to ozone has long-term effects on lung function $(31,32)$, findings that have some support from animal studies (1). However, interpretation of the existing epidemiologic evidence is hampered by inability to separate the effects of other copollutants from the effects of ozone (33). The present study was originally designed to as- sess the independent effects of ozone by minimizing its correlation with other copollutants, and, as expected, observed long-term average ozone concentrations were not significantly correlated with the other pollutants (Table 2). In light of this, our results provide little support for a substantial long-term effect of ozone on lung function growth in children. This could potentially be explained by misclassification of exposure from using central monitor pollutant levels or by low sensitivity of spirometry to detect small airway effects. However, we observed consistent effects for other pollutants using the same exposure estimation methodology, indicating that the lack of an observed ozone effect is unlikely to be the result of these factors. As shown in Figure 1, the variation across communities in mean ozone concentrations (approximately twofold from least to most polluted) was less than for the other pollutants. This modest range in ozone exposure, in conjunction with the low I/O ratio of ambient ozone, may also explain why we did not observe a significant ozone association.

In summary, we obtained annual lung function measures on a cohort of 3,035 school-aged children over a 4-yr period. After appropriate adjustment for personal and household characteristics, ambient air pollution was correlated with statistically significant, and perhaps physiologically important, decreases in lung function growth. The estimated deficit in annual $\mathrm{FEV}_{1}$ growth rate of $0.9 \%$ per year across the range of $\mathrm{PM}_{10}$ exposure exceeds the $0.2 \%$ annual decrement that has been reported for passive smoke exposure in children (26). The results suggest that exposure to air pollution may lead to a reduction in maximal attained lung function, which occurs early in adult life, and ultimately to increased risk of chronic respiratory illness in adulthood. Data from the remainder of our study will help to elucidate the relationships between respiratory health and long-term exposure to ambient air pollutants, while additional follow-up of the cohort beyond graduation will be necessary to determine whether the observed air pollution-associated deficits in lung function have an impact on adult respiratory health.

Acknowledgment: The authors are very grateful for the important input from our External Advisory Committee composed of David Bates, Morton Lippmann, Jonathan Samet, Frank Speizer, John Spengler, Arthur Weiner, James Whittenberger, and Scott Zeger. In addition, Dane Westerdahl, William Linn, Henry Gong, Jr., and Daniel Stram provided excellent advice. They also acknowledge the cooperation of the school principals and teachers, and the students and their parents in each of the 12 study communities, and the efforts of the field team.

\section{References}

1. Bascom, R., P. Bromberg, D. Costa, R. Devlin, D. Dockery, M. Frampton, W. Lambert, J. Samet, F. Speizer, and M. Utell. 1996. State of the art: health effects of outdoor air pollution. Part 1. Am. J. Respir. Crit. Care Med. 153:3-50.

2. Bascom, R., P. Bromberg, D. Costa, R. Devlin, D. Dockery, M. Frampton, W. Lambert, J. Samet, F. Speizer, and M. Utell. 1996. State of the art: health effects of outdoor air pollution. Part 2. Am. J. Respir. Crit. Care Med. 153:477-498.

3. Particulate air pollution and daily mortality: replication and validation of selected studies, 1995. Phase I report of the Particle Epidemiology Evaluation Project. Health Effects Institute, Cambridge, MA.

4. Linn, W., D. Shamoo, K. Anderson, R. Peng, E. Avol, J. Hackney, and H. J. Gong. 1996. Short-term air pollution exposures and responses in Los Angeles area schoolchildren. J. Exposure Anal. Environ. Epidemiol. 6:449-472.

5. Abbey, D., P. Mills, F. Petersen, and W. Beeson. 1994. Long-term ambient concentrations of total suspended particulates and oxidants as related to incidence of chronic disease in California Seventh-Day Adventists. Environ. Health Perspect. 94:43-50.

6. Peters, J., E. Avol, W. Navidi, S. London, W. Gauderman, F. Lurmann, W. Linn, H. Margolis, E. Rappaport, H. J. Gong, and D. Thomas. 1999. A study of twelve southern California communities with differ- 
ing levels and types of air pollution: I. Prevalence of respiratory morbidity. Am. J. Respir. Crit. Care Med. 159:760-767.

7. Peters, J., E. Avol, W. Gauderman, W. Linn, W. Navidi, S. London, H. Margolis, E. Rappaport, H. Vora, H. J. Gong, and D. Thomas. 1999. A study of twelve southern California communities with differing levels and types of air pollution: II. Effects on pulmonary function. Am. J. Respir. Crit. Care Med. 159:768-775.

8. Wiley, J., J. Robinson, T. Piazza, L. Stork, and K. Pladsen. 1993. Final report-study of children's activity patterns.

9. Wang, X., D. Dockery, D. Wypij, D. Gold, F. Speizer, J. Ware, and B. J. Ferris. 1993. Pulmonary function growth velocity in children 6 to 18 years of age. Am. Rev. Respir. Dis. 148:1502-1508.

10. SAS/STAT. 1997. Version 6.12: The MIXED procedure. SAS Institute, Cary, NC.

11. Detels, R., D. Tashkin, J. Sayre, S. Rokaw, A. Coulson, F. J. Massey, and D. H. Wegman. 1987. The UCLA population studies of chronic obstructive respiratory disease: 9 . Lung function changes associated with chronic exposure to photochemical oxidants; a cohort study among never-smokers. Chest 92:594-603.

12. Schwartz, J. 1989. Lung function and chronic exposure to air pollution: a cross-sectional analysis of NHANES II. Environ. Res. 50:309-321.

13. Detels, R., D. Tashkin, J. Sayre, S. Rokaw, F. J. Massey, A. Coulson, and D. H. Wegman. 1991. The UCLA population studies of CORD: X. A cohort study of changes in respiratory function associated with chronic exposure to SOx, NOx, and hydrocarbons. Am. J. Public Health 81:350-359.

14. Tashkin, D., R. Detels, M. Simmons, H. Liu, A. Coulson, J. Sayre, and S. Rokaw. 1994. The UCLA population studies of chronic obstructive respiratory disease: XI. Impact of air pollution and smoking on annual change in forced expiratory volume in one second. Am. J. Respir. Crit. Care Med. 149:1209-1217.

15. Ware, J., B. J. Ferris, D. Dockery, J. Spengler, D. Stram, and F. Speizer. 1986. Effects of ambient sulfur oxides and suspended particles on respiratory health of preadolescent children. Am. Rev. Respir. Dis. 133: 834-842.

16. Dockery, D., F. Speizer, D. Stram, J. Ware, J. Spengler, and B. J. Ferris. 1989. Effects of inhalable particles on respiratory health of children. Am. Rev. Respir. Dis. 139:587-594.

17. Dockery, D., J. Cunningham, A. Damokosh, L. Neas, J. Spengler, P. Koutrakis, J. Ware, M. Raizenne, and F. Speizer. 1996. Health effects of acid aerosols on North American children: respiratory symptoms. Environ. Health Perspect. 104:500-505.

18. Braun-Fahrlander, C., J. Vuille, F. Sennhauser, U. Neu, T. Kunzle, L. Grize, M. Gassner, C. Minder, C. Schindler, H. Varonier, and B. Wuthrich. 1997. Respiratory health and long-term exposure to air pollutants in Swiss schoolchildren. SCARPOL Team. Swiss Study on Childhood Allergy and Respiratory Symptoms with Respect to Air Pollution, Climate and Pollen. Am. J. Respir. Crit. Care Med. 155: 1042-1049.
19. Jedrychowski, W., E. Flak, and E. Mroz. 1999. The adverse effect of low levels of ambient air pollutants on lung function growth in preadolescent children. Environ. Health Perspect. 107:669-674.

20. Raizenne, M., L. Neas, A. Damokosh, D. Dockery, J. Spengler, P. Koutrakis, J. Ware, and F. Speizer. 1996. Health effects of acid aerosols on North American children: pulmonary function. Environ. Health Perspect. 104:506-514.

21. Kleeman, M., and G. Cass. 1999. Effect of emissions control strategies on the size and composition distribution of urban particulate air pollution. Environ. Sci. Technol. 33:177-189.

22. Schauer, J., W. Rogge, L. Hildemann, M. Mazurek, G. Cass, and B. Simoneit. 1996. Source apportionment of airborne particulate matter using organic compounds as tracers. Atmosph. Environ. 30:3837-3855.

23. Dijkstra, L., D. Houthuijs, B. Brunekreer, I. Akkerman, and J. Boleij. 1990. Respiratory health effects of the indoor environment in a population of Dutch children. Am. Rev. Respir. Dis. 142:1172-1178.

24. Ware, J., D. Dockery, A. I. Spiro, F. Speizer, and B. J. Ferris. 1984. Passive smoking, gas cooking, and respiratory health of children living in six cities. Am. Rev. Respir. Dis. 129:366-374.

25. Speizer, F., B. Ferris, Jr., Y. Bishop, and J. Spengler. 1980. Respiratory disease rates and pulmonary function in children associated with $\mathrm{NO}_{2}$ exposure. Am. Rev. Respir. Dis. 121:3-10.

26. Berkey, C., J. Ware, D. Dockery, B. J. Ferris, and F. Speizer. 1986. Indoor air pollution and pulmonary function growth in preadolescent children. Am. J. Epidemiol. 123:250-260.

27. Neas, L., D. Dockery, J. Ware, J. Spengler, F. Speizer, and B. J. Ferris. 1991. Association of indoor nitrogen dioxide with respiratory symptoms and pulmonary function in children. Am. J. Epidemiol. 134:204-219.

28. Koenig, J., D. Covert, and W. Pierson. 1989. Effects of inhalation of acidic compounds on pulmonary function in allergic adolescent subjects. Environ. Health Perspect. 79:173-178.

29. Hoek, G., and B. Brunekreef. 1994. Effects of low-level winter air pollution concentrations on respiratory health of Dutch children. Env. Res. 64:136-150.

30. Frischer, T., M. Studnicka, C. Gartner, E. Tauber, F. Horak, A. Veiter, J. Spengler, J. Kuhr, and R. Urbanek. 1999. Lung function growth and ambient ozone: a three-year population study in school children. Am. J. Respir. Crit. Care Med. 160:390-396.

31. Bates, D. 1995. Ozone: a review of recent experimental, clinical, and epidemiological evidence, with notes on causation-Part 1. Can. Respir. J. 2:25-31.

32. Bates, D. 1995. Ozone: a review of recent experimental, clinical, and epidemiological evidence, with notes on causation-Part 2. Can. Respir. J. 2:161-171.

33. Tager, I. 1999. Air pollution and lung function growth: is it ozone? Am. J. Respir. Crit. Care Med. 160:387-389. 